\title{
Quantifying population exposure to airborne particulate matter during extreme events in California due to climate change
}

\author{
A. Mahmud, M. Hixson, and M. J. Kleeman \\ Department of Civil and Environmental Engineering, University of California at Davis, One Shields Ave, Davis CA 95616, \\ USA
}

Correspondence to: M. J. Kleeman (mjkleeman@ucdavis.edu)

Received: 14 December 2011 - Published in Atmos. Chem. Phys. Discuss.: 23 February 2012

Revised: 11 July 2012 - Accepted: 2 August 2012 - Published: 17 August 2012

\begin{abstract}
The effect of climate change on populationweighted concentrations of particulate matter (PM) during extreme pollution events was studied using the Parallel Climate Model (PCM), the Weather Research and Forecasting (WRF) model and the UCD/CIT 3-D photochemical air quality model. A "business as usual" (B06.44) global emissions scenario was dynamically downscaled for the entire state of California between the years 2000-2006 and 2047-2053. Air quality simulations were carried out for 1008 days in each of the present-day and future climate conditions using year-2000 emissions. Population-weighted concentrations of $\mathrm{PM}_{0.1}, \mathrm{PM}_{2.5}$, and $\mathrm{PM}_{10}$ total mass, components species, and primary source contributions were calculated for California and three air basins: the Sacramento Valley air basin (SV), the San Joaquin Valley air basin (SJV) and the South Coast Air Basin (SoCAB). Results over annual-average periods were contrasted with extreme events.

The current study found that the change in annual-average population-weighted $\mathrm{PM}_{2.5}$ mass concentrations due to climate change between 2000 vs. 2050 within any major subregion in California was not statistically significant. However, climate change did alter the annual-average composition of the airborne particles in the SoCAB, with notable reductions of elemental carbon (EC; $-3 \%$ ) and organic carbon $(\mathrm{OC} ;-3 \%)$ due to increased annual-average wind speeds that diluted primary concentrations from gasoline combustion $(-3 \%)$ and food cooking $(-4 \%)$. In contrast, climate change caused significant increases in population-weighted $\mathrm{PM}_{2.5}$ mass concentrations in central California during extreme events. The maximum 24-h average $\mathrm{PM}_{2.5}$ concentration experienced by an average person during a ten-yr period in the SJV increased by $21 \%$ due to enhanced production
\end{abstract}

of secondary particulate matter (manifested as $\mathrm{NH}_{4} \mathrm{NO}_{3}$ ). In general, climate change caused increased stagnation during future extreme pollution events, leading to higher exposure to diesel engines particles $(+32 \%)$ and wood combustion particles $(+14 \%)$ when averaging across the population of the entire state. Enhanced stagnation also isolated populations from distant sources such as shipping $(-61 \%)$ during extreme events. The combination of these factors altered the statewide population-averaged composition of particles during extreme events, with EC increasing by $23 \%$, nitrate increasing by $58 \%$, and sulfate decreasing by $46 \%$.

\section{Introduction}

Air pollution is a persistent public health problem in the United States with over 158 million people living in regions that violate the National Ambient Air Quality Standards (NAAQS) (USEPA, 2008). The pollutant of greatest health concern is airborne particulate matter with aerodynamic diameter smaller than $2.5 \mu \mathrm{m}\left(\mathrm{PM}_{2.5}\right)$. Epidemiological studies have estimated rates of mortality and morbidity associated with $\mathrm{PM}_{2.5}$ (see for example, Samet et al., 2000; Dockery et al., 1993; Pope III et al., 1995) yielding predictions that an average of 24000 people die from exposure to particulate matter each year in the United States (Mokdad et al., 2005). California experiences a disproportionately large fraction of these deaths (Tran et al., 2008) because it is home to two of the air basins that experience some of the highest $\mathrm{PM}_{2.5}$ concentrations each year. The South Coast Air Basin (SoCAB) has $\sim 15$ million residents that experience $24-\mathrm{h}$ average $\mathrm{PM}_{2.5}$ concentrations that are up to $\sim 2.3$ times higher 
than the NAAQS $\left(35 \mu \mathrm{g} \mathrm{m}^{-3}\right)$. The San Joaquin Valley (SJV) has $\sim 3$ million residents that experience 24 -h average $\mathrm{PM}_{2.5}$ concentrations that exceed the NAAQS by a factor of $\sim 2.3$.

Meteorology plays an important role in California's air pollution problems. Persistent stagnation events develop when high pressure systems stall over the air basins, which traps emissions close to sources leading to reduced ventilation of pollutants. Temperature, wind speed, wind direction, and mixing height in the atmosphere play critical roles in determining patterns of air quality over multiple scales of time and space by affecting emissions, chemical composition, atmospheric transformation, and deposition of particles (Kinney et al., 2008; Pye et al., 2009; Dawson et al., 2009). Global climate change is likely to alter these meteorological parameters affecting air quality (see for example, Kleeman, 2008; Aw and Kleeman, 2003; Sillman et al., 1995) and human health.

Several previous studies have examined how climate change influences ozone concentrations leading to effects on human health (see for example, Bell et al., 2007; West et al., 2007; Knowlton et al., 2004). The potential effects of climate change on airborne fine particulate matter $\left(\mathrm{PM}_{2.5}\right)$ are of even greater importance because elevated $\mathrm{PM}_{2.5}$ is more strongly associated with increased human mortality. In a European study, Dias et al. (2012) showed that climate change alone is likely to increase $\mathrm{PM}_{10}$-induced premature mortality by $8 \%$ in Portugal under the IPCC-SRES (Intergovernmental Panel on Climate Change - Special Report Emissions Scenarios) A2 scenario by the year 2100. In the United States, Jacobson (2008) studied the causal link between $\mathrm{CO}_{2}$ and human mortality, estimating that the direct effect of $\mathrm{CO}_{2}$ emissions on atmospheric stability around urban areas leads to $\sim 1000$ additional air pollution related deaths each year of which $60 \%$ were attributable to increased $\mathrm{PM}_{2.5}$. While this result is interesting, it does not directly quantify climate change effects on $\mathrm{PM}_{2.5}$. Climate change can affect $\mathrm{PM}_{2.5}$ by changing water vapor content in the atmosphere in the future (see for example, Unger et al., 2006; Liao et al., 2006; Pye et al., 2009) or by altering wet deposition rates. Racherla and Adams (2006) reported that climate change is likely to increase surface $\mathrm{PM}_{2.5}$ concentrations in the eastern USA due to decreased precipitation and increased secondary formation (2050's vs. 1990's). In contrast, Tagaris et al. (2007) estimated a $10 \%$ decrease of future $\mathrm{PM}_{2.5}$ concentrations throughout the USA due to increased future precipitation. Tagaris et al. (2009) extended their analysis to investigate the potential impact of climate change on $\mathrm{PM}_{2.5}$ related health effects for the United States using the Environmental Protection Agency (EPA's) Environmental Benefits Mapping and Analysis Program (BenMAP). The authors predicted that the national average premature mortality is likely to increase by 4000 cases in 2050 compared to 2001 along with both increasing and decreasing mortality trends in different states due to climate change alone. California was predicted to experience an average decrease of 186 cases of premature death with decreasing trends also predicted for other $\mathrm{PM}_{2.5}$-related health issues including chronic and acute bronchitis, asthma, hospital admissions, and respiratory diseases in the future. This health effects analysis was a valuable first estimate but it was based on a discrete set of simulations that had limited ability to characterize the inter-annual variability that drives the uncertainty in annual-average exposure periods or the extreme events that drive the uncertainty in the 24-h average exposure periods.

The objective of the current study is to quantify the impact of climate change on population-weighted concentrations of $\mathrm{PM}_{0.1}, \mathrm{PM}_{2.5}$, and $\mathrm{PM}_{10}$ mass in California over annual averages and during extreme 24 -h periods. The analysis is based on more than 1000 simulated days of present climate and 1000 simulated days of future climate with $8-\mathrm{km}$ spatial resolution that span enough years to capture inter-annual variability associated with large scale patterns such as El Niño Southern Oscillation (ENSO) cycles. The large number of simulation days also provides enough information about the extreme values of the distribution to support a rigorous analysis of these extreme events. The results are put into proper context by quantifying the magnitude of the climate effect relative to the uncertainty in the analysis.

\section{Methods}

The impact of climate change on regional air quality over the entire state of California was studied using the Parallel Climate Model (PCM), the Weather Research and Forecasting (WRF) model, and the latest generation of the UCD/CIT air quality model. A schematic diagram and detailed description of the modeling system is presented elsewhere (Mahmud et al., 2010). An overview of the modeling system is presented below.

PCM (Washington et al., 2000) data generated under the "business as usual" (B06.44) global emissions scenario as part of the IPCC 4th Assessment Report (AR4) (Randall et al., 2007) were dynamically downscaled to 4-km resolution using the WRF model version 2.2 (Skamarock, 2004) for present-day (2000-06) and future (2047-53) time periods. The original PCM dataset was generated for a continuous period from 1995 to 2099 with only $\mathrm{CO}_{2}$ increasing by $1 \%$ per year. This emissions scenario was judged to scientifically represent climate change as described in AR4. Note that other factors that contribute to global climate change including increase in methane emissions and changes to anthropogenic aerosols were not considered for the BAU (B06.44) setup of the PCM simulations. Simulations that are currently underway for the IPCC's Fifth Assessment Report (AR5) considered increases in methane emissions and changes to anthropogenic aerosols. However, output from these sophisticated simulations is still not available to the greater scientific community at this time. The climate response predicted by PCM over California was generally lower than the 
ensemble average of the 23 models utilized in AR4 meaning that the predicted climate forcing on the air pollution system may be a conservative estimate.

The WRF model was optimized for California simulations with the physics schemes described by Mahmud et al. (2010). A total of 153 days equally divided into nine periods of 17 days each were simulated for each year. Gaps of 25 days were left between simulation periods to evenly distribute the active days starting on Jan 1 throughout the year. The details of the PCM data down-scaling technique have been provided by Zhao et al. (2011a). WRF simulations of the free atmosphere (above the PBL) were nudged for wind (u,v,w), humidity, and temperature. Sea surface temperatures were also nudged. Other variables inside the PBL were not nudged. The WRF output was saved at UTC (Coordinated Universal Time) hours, which required down-scaling of 17 days for a 16-day air quality simulation period in order to account for the time difference between the UTC and the PST (Pacific Standard Time). This pattern captures an unbiased sample of 1008 days over each of the seven-yr periods. The WRF 4-km fields were averaged to $8-\mathrm{km}$ for the air quality simulations to increase the speed of the calculations without sacrificing significant accuracy in the final results (see for example, Ying et al., 2008). The final air quality modeling domain was composed of $131 \times 128 \times 10$ grid cells $(x-y-z)$ spanning the entire state of California with a first vertical height of $30 \mathrm{~m}$ and a total vertical depth of $5 \mathrm{~km}$ above ground.

The base-case raw emissions inventories for the year 2000 were obtained from the California Air Resources Board (CARB) and the South-Coast Air Quality Management District (SCAQMD). Emissions for both the future and presentday simulations were kept at year 2000 levels so that the results directly quantify the effect of changing climate and background concentrations. On-road mobile source emissions and biogenic volatile organic emissions were adjusted for the variation of meteorological conditions experienced during each simulation using CARB's Emissions Factors (EMFAC) model (CARB, 2007), and biogenic emissions inventory processing model (BEIGIS) (Scott and Benjamin, 2003), respectively. The techniques to adjust these emissions are summarized by Mahmud et al. (2010). Source-oriented and gridded hourly emissions were generated by merging the adjusted on-road mobile and biogenic sources with the original area and point source emissions. Seasonally variable initial conditions (ICs) and boundary conditions (BCs) of gasphase and particle-phase species were specified for the air quality model calculations. A total of 25 model species including ozone, oxides of nitrogen $\left(\mathrm{NO}_{\mathrm{x}}\right)$, peroxy acetyl nitrate (PAN), isoprene, elemental carbon (EC), nitrate, sulfate and ammonium ions were assigned initial and boundary concentrations for the current work. Seasonal variations in background concentrations were also taken into account for the boundary conditions. For example, the boundary condition for ozone along the Pacific coast was set to $35 \mathrm{ppb}$ for fall and winter and $40 \mathrm{ppb}$ for spring and summer seasons. A de-

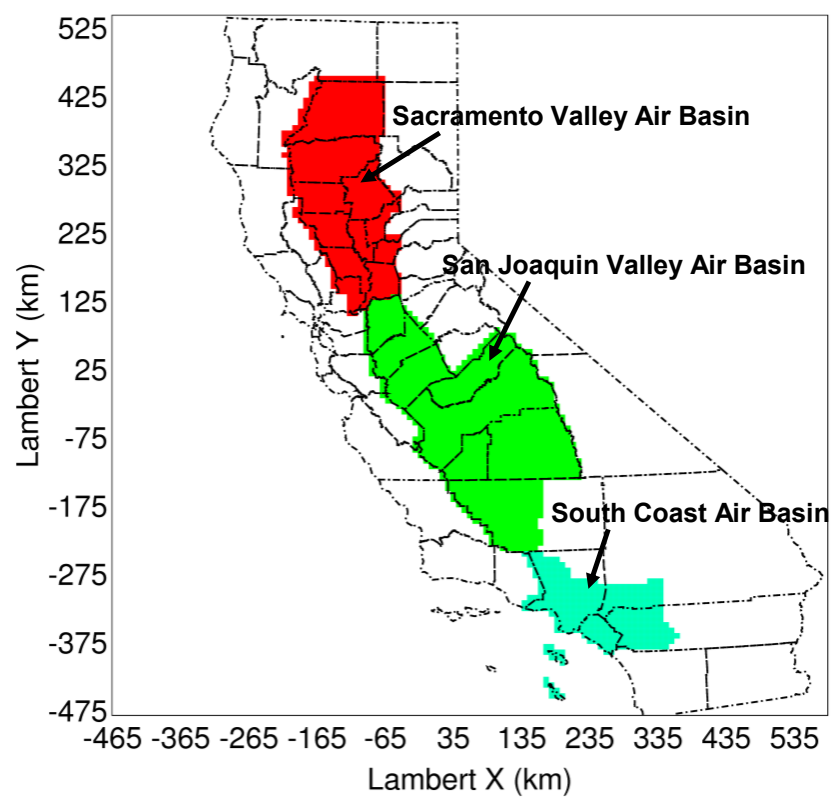

Fig. 1. Three major air basins in California: (1) Sacramento Valley Air Basin (SV), (2) San Joaquin Valley Air Basin (SJV), and (3) South Coast Air Basin (SoCAB). Note that the lines in the state map represents county boundaries in California.

tailed summary of the ICs and BCs utilized in the current study can be found in Mahmud et al. (2010).

The source oriented UCD/CIT 3-D photochemical model (see for example, Ying et al., 2008; Held et al., 2004; Kleeman and Cass, 2001; Kleeman et al., 1997; Mysliwiec and Kleeman, 2002; Ying and Kleeman, 2003; Ying and Kleeman, 2006) was updated in the current study (Mahmud et al., 2010) with a scheme to re-calculate vertical wind to enforce mass conservation. The fully dynamic treatment of gas-particle conversion using the Aerosol Inorganic Module (AIM) thermodynamic code (Wexler and Seinfeld, 1992) was replaced by the approach proposed by Jacobson (2005) using the ISORROPIA II thermodynamics package (Fountoukis and Nenes, 2007; Nenes et al., 1998) to calculate the vapor pressure of semi-volatile inorganic species above each particle surface. The revised model also includes a new wet deposition scheme and a sea salt emissions scheme. In the source-oriented model, pollutants emitted from different sources are tracked separately through all major aerosol processes including emissions, transport, deposition, gas-phase reactions, gas-particle conversion and coagulation. For the current study, secondary PM components (nitrate, sulfate, and ammonium) were tracked as a full external mixture while primary PM components were tracked using inert internal tracers. The inert tracer technique allows the model to efficiently preserve source information throughout the aerosol evolution processes, but it does not provide the capability to predict how source-oriented particles will influence local meteorology. Figure 1 shows the air quality modeling domain 
Table 1. Population-weighted annual average concentrations $\left(\mu \mathrm{g} \mathrm{m}^{-3}\right)$ of $\mathrm{PM}_{2.5}$ total mass, major component species, metal and sources contributing to total primary mass for the present-day (2000-2006) for California (CA), and three air basins: Sacramento Valley (SV), San Joaquin Valley (SJV) and South Coast Air Basin (SoCAB). The error shown is one standard deviation.

\begin{tabular}{lcccc}
\hline Species/Category & CA & SV & SJV & SoCAB \\
\hline Total mass & $8.66 \pm 0.39$ & $7.22 \pm 0.71$ & $8.35 \pm 0.78$ & $10.90 \pm 0.38$ \\
Elemental carbon (EC) & $0.33 \pm 0.02$ & $0.34 \pm 0.03$ & $0.30 \pm 0.02$ & $0.38 \pm 0.01$ \\
Organic carbon (OC) & $2.04 \pm 0.07$ & $2.48 \pm 0.23$ & $1.66 \pm 0.12$ & $2.56 \pm 0.04$ \\
Nitrate (N(V)) & $1.19 \pm 0.15$ & $0.87 \pm 0.22$ & $1.61 \pm 0.32$ & $1.56 \pm 0.18$ \\
Sulfate (S(VI)) & $0.72 \pm 0.05$ & $0.47 \pm 0.06$ & $0.59 \pm 0.06$ & $0.87 \pm 0.06$ \\
Ammonium (N(-III)) & $0.67 \pm 0.06$ & $0.47 \pm 0.09$ & $0.80 \pm 0.11$ & $0.85 \pm 0.07$ \\
Trace metal (METL) & $0.45 \pm 0.02$ & $0.33 \pm 0.02$ & $0.45 \pm 0.03$ & $0.59 \pm 0.02$ \\
Dust & $2.60 \pm 0.10$ & $1.65 \pm 0.11$ & $2.46 \pm 0.18$ & $3.47 \pm 0.13$ \\
Shipping & $0.09 \pm 0.00$ & $0.00 \pm 0.00$ & $0.01 \pm 0.00$ & $0.15 \pm 0.01$ \\
Wood Smoke & $0.86 \pm 0.07$ & $2.39 \pm 0.24$ & $1.52 \pm 0.12$ & $0.37 \pm 0.03$ \\
Diesel Combustion & $0.42 \pm 0.02$ & $0.39 \pm 0.04$ & $0.33 \pm 0.03$ & $0.56 \pm 0.02$ \\
Gasoline Combustion & $0.21 \pm 0.01$ & $0.10 \pm 0.01$ & $0.07 \pm 0.01$ & $0.37 \pm 0.01$ \\
Meat Cooking & $0.74 \pm 0.02$ & $0.13 \pm 0.01$ & $0.14 \pm 0.01$ & $1.40 \pm 0.03$ \\
High Sulfur Content Fuels & $0.23 \pm 0.01$ & $0.06 \pm 0.01$ & $0.07 \pm 0.01$ & $0.31 \pm 0.01$ \\
Miscellaneous & $0.62 \pm 0.02$ & $0.48 \pm 0.04$ & $0.51 \pm 0.03$ & $0.85 \pm 0.02$ \\
\hline
\end{tabular}

and three air basins of interest: the Sacramento Valley air basin (SV), the San Joaquin Valley air basin (SJV) and the South Coast Air Basin (SoCAB). Population-weighted concentrations of particles were calculated for these air basins and for the entire state of California so that the impacts of climate change on public health via changes to air quality could be viewed more directly. The original 2000 population census data for California were extracted in an $8-\mathrm{km}$ resolution gridded domain to match the air quality domain for the current work. The census data show high density of people living in and around major urban areas compared to rest of the state. According to the 2000 census California has a total population of 33.9 million, with a total land area of $4.24 \times 10^{5} \mathrm{~km}^{2}$. The population of the SV was 2.4 million with an area of $0.38 \times 10^{5} \mathrm{~km}^{2}$, the population of the SJV was 3.2 million with an area of $0.60 \times 10^{5} \mathrm{~km}^{2}$, and the population of the SoCAB was 14.6 million with an area of $0.18 \times 10^{5} \mathrm{~km}^{2}$. The population density and population spatial distribution were held constant at year 2000 census values in all present and future year simulations to be consistent with the assumption of constant emissions. This approach produces results that directly illustrate the effects of climate change without confounding factors. The populationweighted concentration is calculated as $\sum_{i=1}^{n} \frac{p_{i} \times C_{i}}{p_{\text {tot }}}$, where $i$ designates each computational cell in the domain, $p_{i}$ is the population at a given cell location, $C_{i}$ is the particulate concentration in the same cell location, and $p_{\text {tot }}$ is the total population in the domain of interest (i.e. air basin wide total population).
PM concentrations averaged over 24-h periods were analyzed using the open source statistical software $\mathrm{R}$ version 2.10.0 with the University Cooperation for Atmospheric Research (UCAR) extremes toolkit version 1.62. Data from the present-day (2000-06) and future (2047-53) were analyzed separately, and the climate change impact was quantified by taking the difference between them. The 10-yr return level and its associate parameters were calculated based on the Generalized Pareto Distribution (GPD) probability model first introduced by Pickands (1975). In this method, the extreme values greater than some threshold are typically assumed to have the following density function:

$$
F(x ; k, \sigma)=\left\{\begin{array}{l}
1-\left(1-\frac{k x}{\sigma}\right)^{\frac{1}{k}} ; k \neq 0, \sigma>0 \\
1-\exp \left(-\frac{x}{\sigma}\right) ; k=0, \sigma>0
\end{array}\right.
$$

where $k$ and $\sigma$ are shape and scale parameters; $x>0$ for $k \leq 0$ and $0<x<\sigma / k$ for $k>0$. There has been a great interest in applying the GPD model to analyze extreme events in environmental datasets (see for example, Brabson et al., 2000; Pisarenko and Sornette, 2003; Li et al., 2005; Jagger et al., 2006; Coles and Tawn, 1991; Coles, 2001) . The threshold value for each variable of interest in both the present-day and future datasets was chosen based on the distribution of all data points, which was approximately equivalent to the $3 \mathrm{rd}$ quantile value of the ranked dataset. The $90 \%$ confidence intervals (CI) of 10-yr return levels were also calculated in this study.

The goal of the current paper is to resolve the effects of climate change alone on conditions conducive to extreme $\mathrm{PM}_{2.5}$ concentrations in California. For this reason, the other variables including population, population density, and base-case emissions were held constant at 2000 level. The comparison 
of climate effects vs. these other effects on extreme pollution events will be analyzed in a future study.

\section{Results}

Table 1 summarizes the population-weighted annual average concentrations of $\mathrm{PM}_{2.5}$ total mass, component species, and primary sources for the present-day (2000-06). The highest calculated population-weighted annual $\mathrm{PM}_{2.5}$ total mass concentration was $\sim 11 \mu \mathrm{g} \mathrm{m}^{-3}$ in the SoCAB followed by $\sim 8 \mu \mathrm{g} \mathrm{m}^{-3}$ in the SJV and $\sim 7 \mu \mathrm{g} \mathrm{m}^{-3}$ in the SV. Populationweighted total mass concentration for the entire state of California was $\sim 9 \mu \mathrm{g} \mathrm{m}^{-3}$. Organic carbon (OC) (mostly primary) is the major component of this total mass $(\sim 24 \%)$, followed by secondary nitrate $(\sim 14 \%)$. Dust is the major contributor to the total primary mass followed by wood smoke, meat cooking, miscellaneous, diesel combustion, high sulfur content fuels, gasoline combustion, and shipping. The performance of the UCD/CIT model in predicting air quality over climatically relevant time periods was evaluated comprehensively by Mahmud et al. (2010). Predicted annual average total and speciated mass concentrations of fine particulate matter $\left(\mathrm{PM}_{2.5}\right)$ were compared with measured concentrations at six representative sites in heavily populated air basins in California for the present-day (2000-2006) period. The air quality model under-estimated annual average $\mathrm{PM}_{2.5}$ mass concentrations by 4-39\% due to over-predictions in downscaled wind speed. Measured annual average $\mathrm{PM}_{2.5}$ total mass concentrations were $\sim 20 \pm 2 \mu \mathrm{g} \mathrm{m}^{-3}$ in the So$\mathrm{CAB}$ and SJV compared to predicted concentrations of $\sim 13$ $18 \mu \mathrm{g} \mathrm{m}^{-3}$. The model also under-predicted components of PM mass such as elemental carbon, organic carbon, nitrate and sulfate due to these same wind speed over predictions. The bias in downscaled wind speed is assumed to be constant in present and future climate periods so that the comparisons between these periods are valid.

\subsection{Annual average PM concentrations}

The differences between future (2047-2053) and present-day (2000-2006) population-weighted annual average concentrations of $\mathrm{PM}_{2.5}$ are displayed in Fig. 2 for the entire state of California and the three major air basins highlighted in Fig. 1. Concentrations of total mass, major components, and primary particle source categories were calculated. The error bars in these figures represent $90 \%$ confidence intervals for the mean difference based on the inter-annual variability within each analysis period.

Population-weighted annual average concentrations of $\mathrm{PM}_{2.5}$ total mass were predicted to decrease by $\sim 2 \%$ from the present-day conditions in the SoCAB with little change predicted for the SV and SJV. Concentrations of all major $\mathrm{PM}_{2.5}$ components such as elemental carbon (EC), organic carbon (OC), sulfate (S(VI)), and ammonium ion (N(-

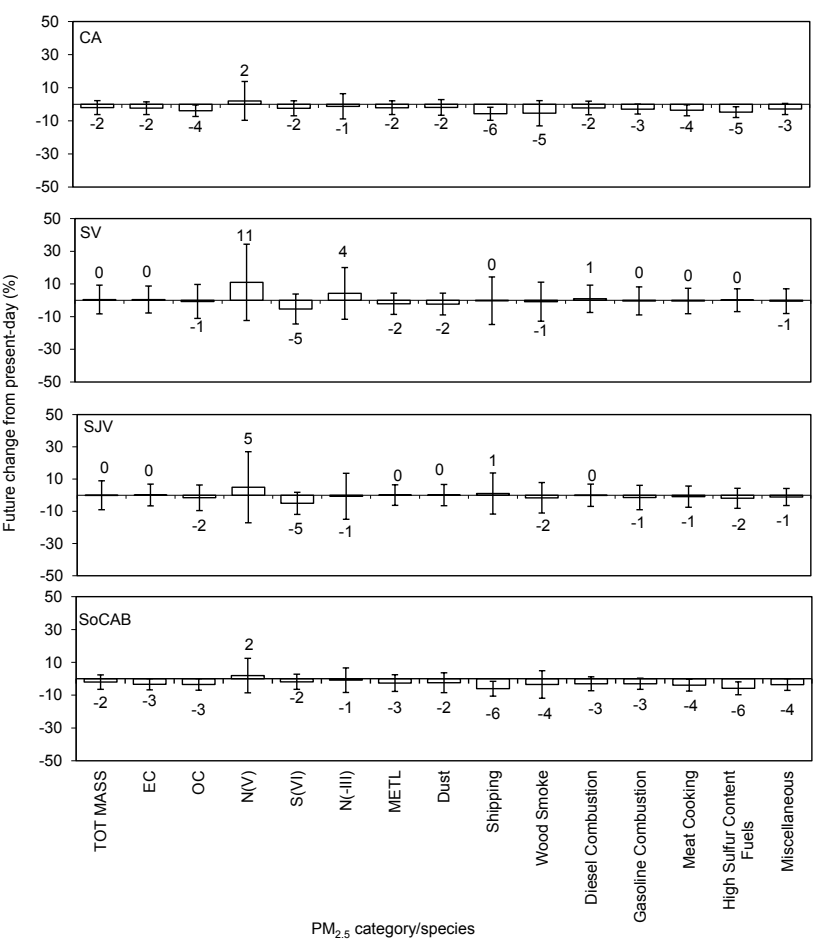

Fig. 2. Future (2047-2053) change in population-weighted annualaverage concentrations of $\mathrm{PM}_{2.5}$ total mass, primary and secondary components, and source categories contributing to the total mass from present-day (2000-2006). Panels (top-down) show California state-wide average, Sacramento Valley (SV) air basin average, San Joaquin Valley (SJV) air basin average, and South Coast Air Basin (SoCAB) average results. The error bars represent the $90 \% \mathrm{CI}$.

III)) followed this downward trend. In contrast, statewide population-weighted concentrations of $\mathrm{PM}_{2.5}$ nitrate $(\mathrm{N}(\mathrm{V}))$ increased by $\sim 2 \%$. Population-weighted primary $\mathrm{PM}_{2.5}$ concentrations in California from all sources including dust, shipping, wood smoke, diesel combustion, gasoline combustion, meat cooking, high sulfur content fuels, and miscellaneous were predicted to decrease by between $\sim 2-6 \%$ due to climate change alone (ignoring changes to future emissions).

Figures S1 and S2 in the Supplement present the analysis illustrated for Fig. 2 for the $\mathrm{PM}_{0.1}$ and $\mathrm{PM}_{10}$ size fractions with largely the same conclusion that the future analysis period tends to have lower annual-average population-weighted concentrations than the present-day analysis period.

Uncertainty analysis must be considered to put the results illustrated in Fig. 2 into proper context. The error bars in this figure represent the $90 \%$ confidence interval based on the inter-annual variability within each analysis period. The most significant feature displayed in this figure is the size of the uncertainty bars induced by inter-annual variability vs. the size of the average change between future and present years. In the majority of cases, the magnitude of the inter-annual variability is greater than the average change between future and present years. For example, the $90 \%$ CI 
for climate-induced change to statewide population-averaged $\mathrm{PM}_{2.5}$ concentrations ranges from $-6 \%$ to $2 \%$ making it not statistically significant. The only exception to this trend is a $4 \%$ (90\% CI: $-7.5 \%$ to $-0.5 \%$ ) reduction in OC concentrations caused by reduced contributions from primary combustion sources such as gasoline combustion $(-3 \%)$ and meat cooking $(-4 \%)$ in the SoCAB.

The fact that $90 \%$ confidence intervals displayed in Fig. 2 (also in Figs. S1 and S2 in the Supplement) largely overlap zero implies that a random selection of different years within each climate period could lead to either positive or negative effects on concentrations. The Intergovernmental Panel on Climate Change (IPCC) Third Assessment Report (AR3) (2001) and the Fourth Assessment Report (AR4) (2007) projected future global changes relative to the present-day based on 30-yr (1960-1989) and 20-yr (1980-1999) averages, respectively. In the current study, only $\sim 40 \%$ of the days within seven-yr periods in the present-day (2000-2006) and future (2047-2053) were simulated. The reduced analysis window greatly lowers the computational burden of the problem while still capturing the inter-annual variability associated with the ENSO cycle. The inter-annual variability for $\mathrm{PM}_{2.5}$ has previously been shown in Fig. 5 by Mahmud et al. (2010) for present and future climate periods. The relative standard deviations (standard deviation divided by the mean) are $2 \%, 3 \%, 6 \%$, and $9 \%$ for the present (2000-2006), and $5 \%, 6 \%, 8 \%$, and $7 \%$ for the future (2047-2053) periods at Riverside, central Los Angeles, Bakersfield, and Fresno, respectively. The value of $9 \%$ relative standard deviation for Fresno in the current climate compares favorably to the measured value of $10.5 \%$ relative standard deviation for the San Joaquin Valley between the years 2000-2007 (statistics calculated from monitoring data available at arb.ca.gov). The uncertainty range in the comparison between present and future climate is inversely proportional to the square root of $n$ (= number of simulated days). The current results span more days of air quality in California than any previous study and so they provide a best estimate for the effect of climate on annual-average population-weighted PM concentrations in California. Even with 1008 simulated days, the length of the analysis periods must be expanded to calculate a full set of statistically significant changes.

It must also be recognized that the inter-annual variability is only one source of uncertainty in the climate-air quality calculation. Most notably, the uncertainties introduced by the choice and configuration of the Global Climate Model (GCM), Regional Climate Model (RCM), and air quality models are not included in the current analysis (or any previous analysis). Running a complete ensemble of calculations over a full 20-yr analysis period would fully characterize this uncertainty, but this effort was beyond the scope of the current study.

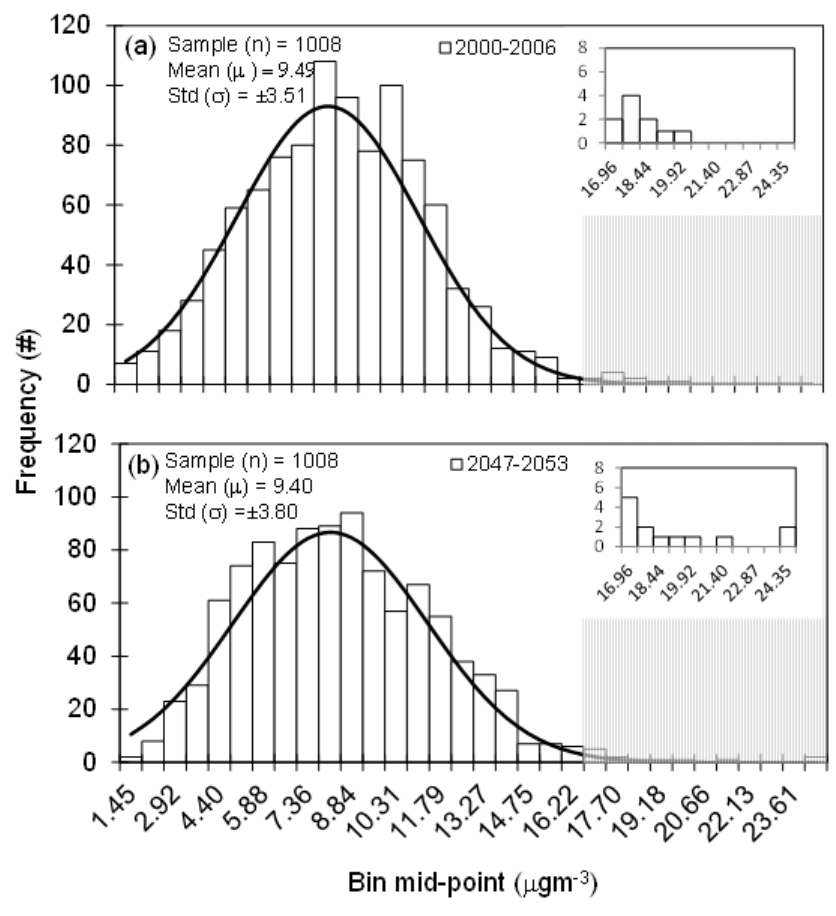

Fig. 3. Frequency distribution of 24-h average population-weighted $\mathrm{PM}_{2.5}$ total mass concentrations for California under the (a) present-day (2000-2006) and (b) future (2047-2053) climate conditions. The shaded regions encompass values higher than the 99th percentile value of each distribution, and insets show details of the shaded regions in the distributions.

\subsection{Extreme events}

The frequency distributions of population-weighted dailyaverage $\mathrm{PM}_{2.5}$ total mass concentrations have similar shapes for the 1008 days of present climate (panel a) and the 1008 days of future climate (panel b) in Fig. 3, but the upper tails of these distributions exhibit different behavior. Notably, the extreme concentration events defined to be the highest $1 \%$ of the predicted concentrations (99th percentile) range from $16.5-19.2 \mu \mathrm{g} \mathrm{m}^{-3}$ in the present climate and 16.6$24.7 \mu \mathrm{g} \mathrm{m}^{-3}$ in the future climate. Short-term extreme concentrations of $\mathrm{PM}_{0.1}, \mathrm{PM}_{2.5}$ and $\mathrm{PM}_{10}$ have public health implications through acute mortality or through their contributions to chronic exposure (see for example, Seaton et al., 1995; Welty and Zeger, 2005; Ebelt et al., 2000; Peters et al., 1997). Further analysis was carried out to understand the effects of climate change on extreme PM concentrations in California.

Figure 4 shows the average $\mathrm{PM}_{2.5}$ total mass concentrations corresponding to the 10 days with the highest population-weighted $\mathrm{PM}_{2.5}$ concentrations in California (99th percentile extreme concentrations). Panel a shows the 10-day average concentrations for the future extreme events (2047-2053), panel b shows the 10-day average concentrations for the present-day extreme events (2000-2006), and 
(a) Future (2047-2053)

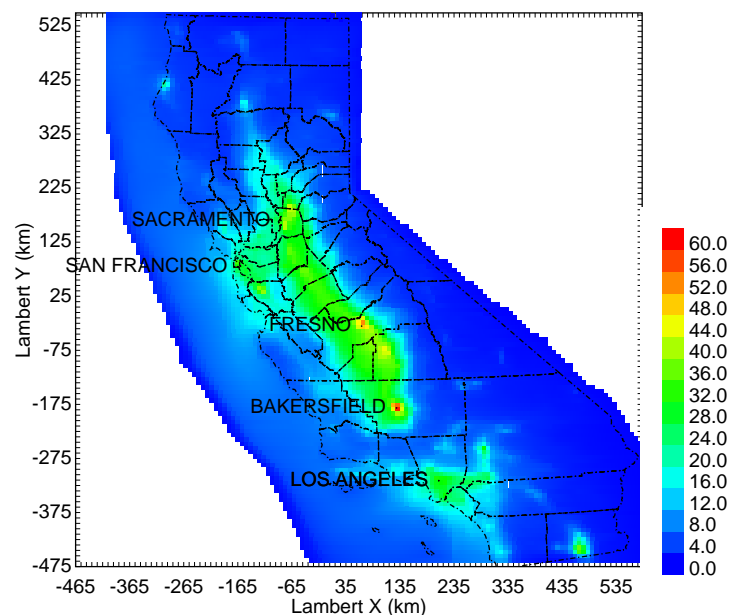

(b) Present (2000-2006)

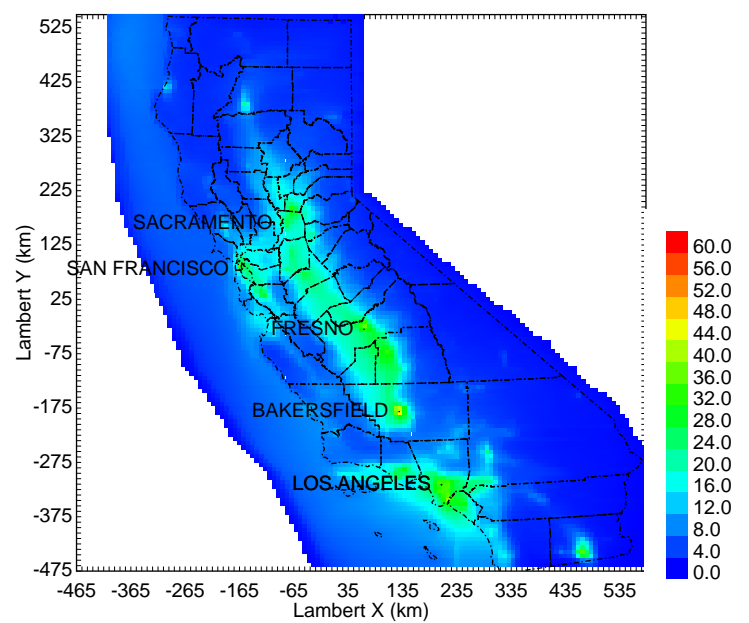

(c) Future - Present

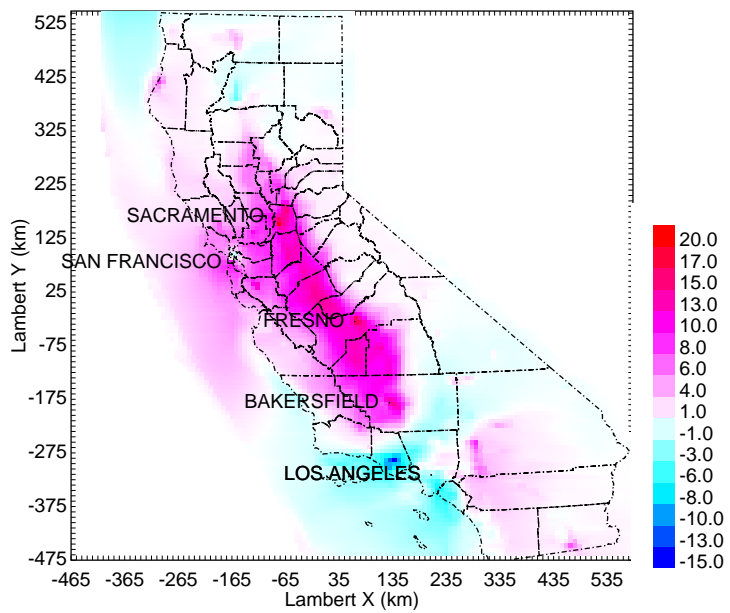

Fig. 4. Average of worst 24-h average $\mathrm{PM}_{2.5}$ total mass concentrations $\left(\mu \mathrm{g} \mathrm{m}^{-3}\right)$ corresponding to days with population-weighted concentrations above the 99th percentile values for California under the (a) future (2047-2053), and (b) present-day climate (20002006) conditions. (c) shows the difference between the future (a) and present-day (b). panel $\mathrm{c}$ shows the difference between the future and presentday extreme events.

Extreme events in the future climate are characterized by 99 th percentile $\mathrm{PM}_{2.5}$ concentrations of $\sim 45-55 \mu \mathrm{g} \mathrm{m}^{-3}$ around cities including Bakersfield, Fresno, and Sacramento (panel a). In comparison, extreme events in the present climate exhibit 99th percentile $\mathrm{PM}_{2.5}$ concentrations between $\sim 35-45 \mu \mathrm{g} \mathrm{m}^{-3}$ around major cities (panel b). The extreme concentrations exceed both the California Ambient Air Quality Standard (CAAQS) of $20 \mu \mathrm{g} \mathrm{m}^{-3}$ and the National Ambient Air Quality Standard (NAAQS) of $35 \mu \mathrm{g} \mathrm{m}^{-3}$ for 24-h average $\mathrm{PM}_{2.5}$ total mass concentration. Panel c shows that the extreme 99th percentile concentrations are predicted to in-

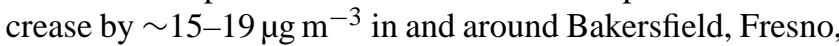
Sacramento, and San Francisco in the future climate compared to present-day. The maximum future increase of $\sim 18$ $20 \mu \mathrm{g} \mathrm{m}^{-3}$ is predicted to occur in areas between Fresno and Bakersfield in the SJV. Extreme $\mathrm{PM}_{2.5}$ concentrations in Los Angeles are predicted to decrease by $\sim 2 \mu \mathrm{g} \mathrm{m}^{-3}$ in the future with larger decreases of $\sim 15 \mu \mathrm{g} \mathrm{m}^{-3}$ predicted in Ventura county west of Los Angeles.

Further statistical analysis was carried out for $\mathrm{PM}_{0.1}$, $\mathrm{PM}_{2.5}$ and $\mathrm{PM}_{10}$ population-weighted 24-h average concentrations based on extreme value analysis (EVA) (Coles, 2001), which included more data points in order to relax the constraint imposed by the 99th percentile values used in the previous analysis. In EVA, the extreme deviation from the median of probability distributions is determined. In the current study, data for both the present-day and future periods were subjected to EVA analysis. Figure 5 displays the change in the population-weighted ten-yr return level for 24-h average $\mathrm{PM}_{2.5}$ concentrations due to climate change between 2000 and 2050. Simply stated, this is the change in maximum 24-h average $\mathrm{PM}_{2.5}$ concentration that an average person would experience in a decade due to climate change. The error bars shown in Fig. 5 represent the lower and upper limits of the $90 \%$ confidence intervals.

The 10-yr return levels for $\mathrm{PM}_{2.5} \mathrm{EC}(+23 \%)$ and $\mathrm{NO}_{3}^{-}$ $(+58 \%)$ averaged over the statewide population were predicted to increase in the future while statewide 10 -yr return levels for $\mathrm{PM}_{2.5} \mathrm{SO}_{4}^{2-}(-46 \%)$ were predicted to decrease. These trends reflect increased stagnation during future pollution events which traps pollutants close to their emissions source and provides greater time for the formation of secondary products. Zhao et al. (2011a, b) also showed that the number of stagnation days, which also lead to high pollution events, will increase in the SJV both in the summer and winter in the future. $\mathrm{NO}_{\mathrm{x}}$ is emitted in close proximity to population centers by combustion sources such as motor vehicles, leading to increased population exposure to $\mathrm{NO}_{\mathrm{x}}$ reaction products such as $\mathrm{NO}_{3}^{-}$when stagnation increases. $\mathrm{SO}_{\mathrm{x}}$ is emitted from industrial facilities and from goods movement sources such as ships, leading to decreased population exposure to $\mathrm{SO}_{\mathrm{x}}$ reaction productions such as $\mathrm{SO}_{4}^{2-}$ when 


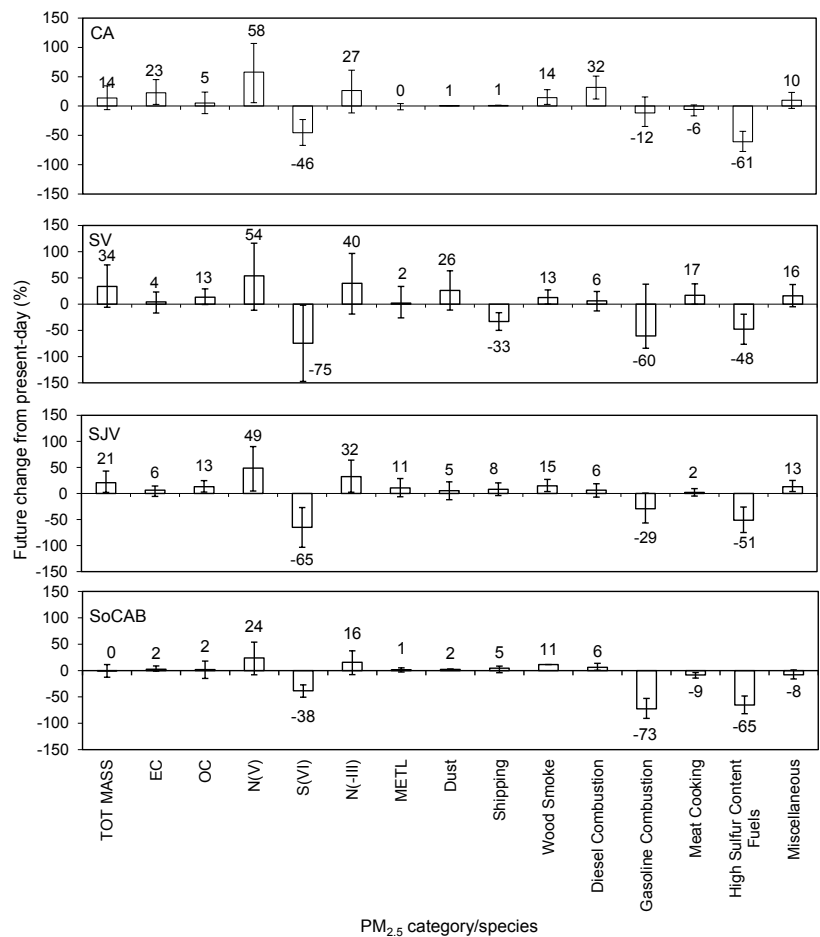

Fig. 5. Change in population-weighted extreme concentrations of $\mathrm{PM}_{2.5}$ total mass, primary and secondary components, and source categories contributing to the total mass between future (20472053) and present-day (2000-2006). Values are the changes in the ten-year return levels which are the maximum 24-h average concentration experienced in a ten year period. Panels (top-down) show California state-wide average, Sacramento Valley (SV) air basin average, San Joaquin Valley (SJV) air basin average, and South Coast Air Basin (SoCAB) average results. The error bars represent the lower and upper limits of the $90 \% \mathrm{CI}$.

stagnation increases. Although $\mathrm{NO}_{3}^{-}$and $\mathrm{SO}_{4}^{2-}$ formation can exhibit non-linear behavior in the presence of changing emissions and changing meteorology, it does not appear that these non-linear effects contribute significantly to climateinduced concentration changes in the current study. For example, the known potential non-linearity of the nitrate system with respect to $\mathrm{NO}_{\mathrm{x}}$ and $\mathrm{VOC}$ concentrations does not appear to be active in the winter stagnation events where background ozone is the dominant oxidant. Increasing background ozone concentrations in the future would compete with strongly decreasing $\mathrm{NO}_{\mathrm{x}}$ emissions in the future, leading to a net reduction in nitrate. These effects are both "linear" to first approximation, even though they act in different directions.

Statewide contributions to primary $\mathrm{PM}_{2.5}$ from diesel engines $(+32 \%)$ and wood burning $(+14 \%)$ increase during future extreme pollution events while contributions from offshore shipping $(-61 \%)$ decrease. Effects during extreme events were felt most strongly in the SJV, producing an increase of $21 \%$ in the $10-\mathrm{yr}$ return level for population- weighted $\mathrm{PM}_{2.5}$ mass in that region, mostly due to increased concentrations of primary $\mathrm{OC}$ and enhanced formation of $\mathrm{NH}_{4} \mathrm{NO}_{3}$ during the future extreme stagnation events. The change in the 10-yr return levels for $\mathrm{PM}_{0.1}$ and $\mathrm{PM}_{1}$ (Figs. S4 and S5 in the Supplement) are qualitatively similar to $\mathrm{PM}_{2.5}$ results.

\section{Discussion}

The effects of climate change on airborne PM mass concentrations in California between the years 2000-2006 and 2047-2053 are generally smaller than the natural interannual variability within either of these periods. Populationweighted concentrations of $\mathrm{PM}_{0.1} / \mathrm{PM}_{2.5} / \mathrm{PM}_{10}$ mass in the SoCAB, SJV, SV, and across the entire state were not statistically different in the future climate vs. the present climate even though 1008 representative days were simulated in each climate period. Likewise, concentrations of PM chemical components and primary source contributions generally did not respond to climate change in a statistically significant fashion other than a few notable exceptions discussed below. The results of these tests are unable to reject the hypothesis that climate change has only a small effect on annual-average population-weighted airborne PM mass in California's major air basins. This implies that any calculation that combines the population-weighted concentrations from $<1000$ sample days with mortality or morbidity coefficients derived from epidemiological studies would likewise be unable to find statistically significant effects of climate change on human health due to changes in annual-average airborne PM mass. Caution must be used when interpreting the results from recent studies that show projected health benefits of climate change via changes to airborne PM in California.

Climate change did alter the annual-average composition of the airborne particles in the SoCAB, with notable reductions of elemental carbon (EC; $-3 \%$ ) and organic carbon $(\mathrm{OC} ;-3 \%)$ due to increased annual-average wind speeds that diluted primary concentrations from gasoline combustion $(-3 \%)$ and food cooking $(-4 \%)$. These trends reflect the increase in annual-average wind speed over coastal portions of California. Future epidemiology studies may be able to quantify health effects associated with changes to individual PM chemical components and/or sources.

An analysis of extreme pollution events suggests that subregions of California will experience increased 99th percentile values of population-weighed concentrations as well as higher 10-yr return levels of primary PM due to climate change. Changes to the source contributions and composition of particles during extreme events are significant when averaged over the population of the entire state. These trends are consistent with the increased strength of future stagnation events which trap pollutants close to the emissions source. Stronger stagnation events increase population-weighted extreme concentrations of emissions released close to major 
cities and decrease the effects of more remote sources. The public health consequences of increased concentrations during extreme events are difficult to predict. Acute exposure to $\mathrm{PM}_{2.5}$ over 24-h periods is associated with health effects including various cardio-vascular diseases (see for example, Pope III et al., 2009; Peters et al., 2001; Brook et al., 2004; Schulz et al., 2005), and aggravated respiratory symptoms i.e. asthma and decreased lung function (see for example, Schwartz and Neas, 2000; Mar et al., 2004; Norris et al., 1999). Assuming that the same susceptible populations respond to long-term exposure and extreme events, then the relevant public health indicator is likely increased concentrations in either exposure category. If different susceptible populations respond to long-term exposure and extreme events, then decreases in one type of exposure will offset the effects of increases in the other exposure. Future epidemiological studies will need to consider these issues in light of the competing climate trends for annual-average vs. extreme PM concentrations in California.

The results of the current paper help quantify the heightened stagnation during extreme events in the future implying that additional controls would be needed to offset the extreme PM climate penalty". The exact magnitude of those additional controls given the existing control plans can be explored in future studies with more refined models that consider feedback effects between source-oriented aerosols and local meteorology.

\section{Supplementary material related to this article is available online at: http://www.atmos-chem-phys.net/12/ 7453/2012/acp-12-7453-2012-supplement.pdf.}

Acknowledgements. This research was funded by the California Air Resources Board under Contract \# 04-349. The statements and conclusions of this report are those of the contractor and not necessarily those of the California Air Resources Board. The mention of commercial products, their source, or their use in connection with material reported herein is not to be construed as actual or implied endorsement of such products.

Edited by: F. Dentener

\section{References}

Aw, J. and Kleeman, M. J.: Evaluating the first-order effect of intraannual temperature variability on urban air pollution, J. Geophys. Res., 108, 4365, doi:10.1029/2002JD002688, 2003.

Brabson, B. B. and Palutikof, J. P.: Tests of the Generalized Pareto Distribution for Predicting Extreme Wind Speeds, J. Appl. Meteorol., 39, 1627-1640, 2000.

Bell, M. L, Goldberg, R., Hogrefe. C., Kinney, P. L., Knowlton, K., Lynn, B., Rosenthal, J., Rosenzweig, C., and Patz, J. A.: Climate change, ambient ozone, and health in 50 US cities, Clim. Change, 82, 61-76, 2007.

Brook, R. D., Franklin, B., Cascio, W. E., Hong, Y., Howard, G., Lipsett, M., Luepker, R., Mittleman, M., Samet, J., Smith Jr., S., and Tager, I.: Air pollution and cardiovascular disease: a statement of the health care professionals from the expert panel on population and prevention science of the Am. Heart Assoc., Circ., 109, 2655-2671, 2004.

California Air Resources Board: The emissions factor (EMFAC) calculation model, available at http://www.arb.ca.gov/ msei/onroad/latest_version.htm, 2007.

Coles, S. G. and Tawn, J. A.: Modelling extreme multivariate events, J. Roy. Stat. Soc. B, 53, 377-392, 1991.

Coles, S.: An introduction to statistical modeling of extreme values, Springer, London, 210 pp., 2001.

Dockery, D. W., Arden Pope, C., Xu, X., Spengler, J. D., Ware, J., H., Fay, M. E., Ferris Jr., B. G., and Speizer, F. E.: An Association between Air-Pollution and Mortality in 6 United-States Cities, New Engl. J. Med., 329, 1753-1759, 1993.

Ebelt, S., Petkau, A., Vedal, S., Fisher, T., and Brauer, M.: Exposure of Chronic Obstructive Pulmonary Disease Patients to Particulate Matter: Relationships between Personal and Ambient Air Concentrations, J. Air Waste Manage., 50, 1081-1094, 2000.

Fountoukis, C. and Nenes, A.: ISORROPIA II: a computationally efficient thermodynamic equilibrium model for $\mathrm{K}^{+}$$\mathrm{Ca}^{2+}-\mathrm{Mg}^{2+}-\mathrm{NH}_{4}^{+}-\mathrm{Na}^{+}-\mathrm{SO}_{4}^{2-}-\mathrm{NO}_{3}^{-}-\mathrm{Cl}^{-}-\mathrm{H}_{2} \mathrm{O}$ aerosols, Atmos. Chem. Phys., 7, 4639-4659, doi:10.5194/acp-7-4639-2007, 2007.

Held, T., Ying, Q., Kaduwela, A., and Kleeman, M.: Modeling particulate matter in the San Joaquin Valley with a source-oriented externally mixed three-dimensional photochemical grid model, Atmos. Environ., 38, 3689-3711, 2004.

Jacobson, M. Z.: A solution to the problem of nonequilibrium acid/base gas-particle transfer at long time step, Aerosol Sci. Technol., 39, 92-103, 2005.

Jacobson, M. Z.: On the causal link between carbon dioxide and air pollution mortality, Geophys. Res. Lett., 35, L03809, doi:10.1029/2007GL031101, 2008.

Jagger, T. H. and Elsner, J. B.: Climatology models for extreme hurricane near the United States, J. Climate, 19, 3220-3236, 2006.

Kinney, P. L.: Climate Change, Air Quality, and Human Health, Am. J. Prev. Med., 35, 459-467, 2008.

Kleeman, M. J.: A preliminary assessment of the sensitivity of air quality in California to global change, Climatic Change, 87, S273-S292, 2008.

Kleeman, M. J., Cass, G. R., and Eldering, A.: Modeling the airborne particle complex as a source-oriented external mixture, J. Geophys. Res. Atmos., 102, doi:10.1029/97JD01261, 2135521372, 1997.

Kleeman, M. J. and Cass, G. R.: A 3D Eulerian source-oriented model for an externally mixed aerosol, Environ. Sci. Technol., 35, 4834-4848, 2001.

Knowlton K., Rosenthal J. E., Hogrefe, C., Lynn, B., Gaffin, S., Goldberg, R., Rosenzweig, C., Civerolo, K., Ku, J., and Kinney, P.: Assessing ozone-related health impacts under a changing climate, Environ. Health Perspect., 112, 1557-1563, 2004.

Liao, H., Chen, W.-T., and Seinfeld, J. H.: Role of climate change in global predictions of future tropospheric ozone and aerosols, $J$. Geophys. Res., 111, D12304, doi:10.1029/2005JD006852, 2006. 
Li, Y., Cai, W., and Campbell, E. P.: Statistical modeling of extreme rainfall in southwest Western Australia, J. Climate, 18, 852-863, 2005.

Mahmud, A., Hixson, M., Hu, J., Zhao, Z., Chen, S.-H., and Kleeman, M. J.: Climate impact on airborne particulate matter concentrations in California using seven year analysis periods, Atmos. Chem. Phys., 10, 11097-11114, doi:10.5194/acp10-11097-2010, 2010.

Mar, T., Larson, T. V., Stier, R. A., Claiborn, C., and Koenig, J.: An Analysis of the Association Between Respiratory Symptoms in Subjects with Asthma and Daily Air Pollution in Spokane, Washington, Inhal. Toxicol., 16, 809-815, 2004.

Mokdad, A. H., Marks, J. S., Stroup, D. F., and Gerberding, J. L.: Actual causes of death in the United States, 2000, J. Amer., Med. Assoc., 291, 1238-1245, 2004.

Mysliwiec, M. J. and Kleeman, M. J.: Source apportionment of secondary airborne particulate matter in a polluted atmospbere, Environ. Sci. Technol., 36, 5376-5384, 2002.

Nenes, A., Pandis, S. N., and Pilinis, C.: ISORROPIA: A new thermodynamic equilibrium model for multiphase multicomponent inorganic aerosols, Aquat. Geochem., 4, 123-152, 1998.

Norris, G., Young Pong, S. N., Koenig, J. Q., Larson, T. V., Sheppard, L., and Stout, J. W.: An association between fine particles and asthma emergency department visits for children in Seattle., Environ Health Perspect., 107, 489-493, 1999.

Peters, A., Wichmann, H., Tuch, T., Heinrich, J., and Heyder J.: Respiratory effects are associated with the number of ultrafine particles, Am. J. Respir. Crit. Care Med., 155, 1376-1383, 1997.

Peters, A., Dockery, D. W., Muller, J. E., and Mittleman, M. A.: Increased Particulate Air Pollution and the Triggering of Myocardial Infarction, Circulation, 103, 2810-2815, 2001.

Pickands, J.: Statistical Inference Using Extreme Order Statistics, Ann. Stat., 3, 119-131, 1975.

Pisarenko, V. F. and Sornette, D.: Characterization of the frequency of extreme earthquake events, Pure Appl. Geophys., 160, 23432364, 2003.

Pope III, C. A., Thun, M. J., Namboodiri, M. M., Dockery, D. W., Evans, J. S., Speizer, F. E., and Heath Jr., C. W.: Particulate AirPollution as a Predictor of Mortality in a Prospective-Study of Us Adults, Am. J. Respir. Crit. Care Med., 151, 669-674, 1995.

Pope III, C. A., Burnett, R. T., Krewski, D., Jerrett, M., Shi, Y., Calle, E., and Thun, M. J.: Cardiovascular mortality and exposure to airborne fine particulate matter and cigarette smoke: shape of the exposure-response relationship, Circulation, 120, 941-948, 2009.

Pye, H. O. T., Liao, H., Wu, S., Mickley, L. J., Jacob, D. J., Henze, D. K., and Seinfeld, J. H.: Effect of changes in climate and emissions on future sulfate-nitrate-ammonium aerosol levels in the United States, J. Geophys. Res. 114, D01205, doi:10.1029/2008JD010701, 2009.

Racherla, P. N., and Adams, P. J.: Sensitivity of global tropospheric ozone and fine particulate matter concentrations to climate change, J. Geophys. Res., 111, D24103, doi:10.1029/2005JD006939, 2006.

Samet, J. M., Dominici, F., Curriero, F. C., Coursac, I., and Zeger, S. L.: Fine particulate air pollution and mortality in 20 US Cities, 1987-1994, New Engl. J. Med., 343, 1742-1749, 2000.

Schulz, H., Harder, V., Ibald-Mulli, A., Khandoga, A., Koenig, W., Krombach, F., Radykewicz, R., Stampfl, a., Thorand, B., and Pe- ters., A.: Cardiovascular effects of fine and ultrafine particles, J. Aerosol Med., 18, 1-22, 2005.

Schwartz, J. and Neas, L. M.: Fine Particles Are More Strongly Associated than Coarse Particles with Acute Respiratory Health Effects in School children, Epidemiology, 11, 6-10, 2000.

Scott, K. and Benjamin, M.: Development of a biogenic volatile organic compounds emission inventory for SCOS97-NARSTO domain, Atmos. Environ., 37, 39-49, 2003.

Seaton, A., Godden, D., McNee, W., and Donaldson, K.: Particulate air pollution and acute health effects, The Lancet, 345, 176-178, 1995.

Sillman, S. and Samson, F. J.: Impact of Temperature on Oxidant Photochemistry in Urban, Polluted Rural and Remote Environments, J. Geophys. Res.-Atmos., 100, 11497-11508, 1995.

Skamarock, W. C.: Evaluating mesoscale NWP models using kinetic energy spectra, Mon. Weather Rev., 132, 3019-3032, 2004.

Tagaris, E., Manomaiphiboon, K., Liao, K. J., Leung, L. R., Woo, J. H., He, S., Amar, P., and Russell, A. G.: Impacts of global climate change and emissions on regional ozone and fine particulate matter concentrations over the United States, J. Geophys. Res., 112, D14312, doi:10.1029/2006JD008262, 2007.

Tagaris, E., Liao, K. J., Delucia, A. J., Deck, L., Amar, P., and Russell, A. G.: Potential Impact of Climate Change on Air PollutionRelated Human Health Effects, Environ. Sci. Technol., 43, 49794988, 2009.

Tran, H. T., Alvarado, A., Garcia, C., Motallebi, N., Miyasato, L., and Vance, W.: Methodology for Estimating Premature Deaths Associated with Long-term Exposure to Fine Airborne Particulate Matter in California, California Environmental Protection Agency, Air Resources Board, Sacramento, CA, USA, 2008.

Unger, N., Shindell, D. T., Koch, D. M., Amann, M., Cofala, J., and Streets, D. G.: Influences of man-made emissions and climate changes on tropospheric ozone, methane, and sulfate at 2030 from a broad range of possible futures, J. Geophys. Res., 111, D12313, 2006.

United States Environmental Protection Agency (USEPA), Latest Findings on National Air Quality: Status and Trends through 2007, Office of the Air Quality Planning, 2008.

Washington, W. M., Weatherly, J. W., Meehl, G. A., Semtner, A. J., Bettge, T. W., Craig, A. P., Strand, W. G., Arblaster, J., Wayland, V. B., James, R., and Zhang, Y.: Parallel climate model (PCM) control and transient simulations, Clim. Dynam., 16, 755-774, 2000 .

Welty, L. and Zeger, S.: Are the Acute Effects of Particulate Matter on Mortality in the National Morbidity, Mortality, and Air Pollution Study the Result of Inadequate Control for Weather and Season? A Sensitivity Analysis using Flexible Distributed Lag Models, Am. J. Epidemiol., 162, 80-88, 2005.

West, J. J., Szopa, S, Hauglustaine, D. A.: Human mortality effects of future concentrations of tropospheric ozone, CR Geoscience, 339, 775-783, 2007.

Wexler, A. S. and Seinfeld, J. H.: Analysis of Aerosol AmmoniumNitrate - Departures from Equilibrium during Scaqs, Atmos. Environ. A-Gen., 26, 579-591, 1992.

Ying, Q., Lu, J., Allen, P., Livingstone, P., Kaduwela, A., and Kleeman, M.: Modeling air quality during the California Regional $\mathrm{PM}_{10} / \mathrm{PM}_{2.5}$ Air Quality Study (CRPAQS) using the UCD/CIT source-oriented air quality model - Part I: Base case model results, Atmos. Environ., 42, 8954-8966, 2008. 
Ying, Q. and Kleeman, M. J.: Effects of aerosol UV extinction on the formation of ozone and secondary particulate matter, Atmos. Environ., 37, 5047-5068, 2003.
Ying, Q. and Kleeman, M. J.: Source contributions to the regional distribution of secondary particulate matter in California, Atmos. Environ., 40, 736-752, 2006. 